\title{
Neuroprotective and neurorestorative signal transduction mechanisms in brain aging: modification by genes, diet and behavior
}

\author{
Mark P. Mattson ${ }^{\mathrm{a}, \mathrm{b}, *}$, Wenzhen Duan ${ }^{\mathrm{a}}$, Sic L. Chan ${ }^{\mathrm{a}}$, Aiwu Cheng ${ }^{\mathrm{a}}$, Norman Haughey ${ }^{\mathrm{a}}$, \\ Devin S. Gary ${ }^{\mathrm{a}}$, Zhihong Guo ${ }^{\mathrm{a}}$, Jaewon Lee ${ }^{\mathrm{a}}$, Katsutoshi Furukawa ${ }^{\mathrm{a}}$ \\ a Laboratory of Neurosciences, National Institute on Aging Gerontology Research Center 4F01, \\ 5600 Nathan Shock Drive, Baltimore, MD 21224, USA \\ b Department of Neuroscience, Johns Hopkins University School of Medicine, 725 N. Wolfe Street, Baltimore, MD 21205, USA
}

Received 11 July 2001; received in revised form 14 December 2001; accepted 26 December 2001

\begin{abstract}
Cells in the brain deploy multiple mechanisms to maintain the integrity of nerve cell circuits, and to facilitate responses to environmental demands and promote recovery of function after injury. The mechanisms include production of neurotrophic factors and cytokines, expression of various cell survival-promoting proteins (e.g. protein chaperones, antioxidant enzymes, Bcl-2 and inhibitor of apoptosis proteins), protection of the genome by telomerase and DNA repair proteins, and mobilization of neural stem cells to replace damaged neurons and glia. The aging process challenges such neuroprotective and neurorestorative mechanisms, often with devastating consequences as in Alzheimer's disease (AD), Parkinson's and Huntington's diseases and stroke. Genetic and environmental factors superimposed upon the aging process can determine whether brain aging is successful or unsuccessful. Mutations in genes that cause inherited forms of AD (amyloid precursor protein (APP) and presenilins), Parkinson's disease ( $\alpha$-synuclein and parkin) and trinucleotide repeat disorders (e.g. huntingtin and the androgen receptor) overwhelm endogenous neuroprotective mechanisms. On the other hand, neuroprotective mechanisms can be bolstered by dietary (caloric restriction, and folate and antioxidant supplementation) and behavioral (cognitive and physical activities) modifications. At the cellular and molecular levels, successful brain aging can be facilitated by activating a hormesis response to which neurons respond by upregulating the expression of neurotrophic factors and stress proteins. Neural stem cells that reside in the adult brain are also responsive to environmental demands, and appear capable of replacing lost or dysfunctional neurons and glial cells, perhaps even in the aging brain. The recent application of modem methods of molecular and cellular biology to the problem of brain aging is revealing a remarkable capacity within brain cells for adaptation to aging and resistance to disease.
\end{abstract}

(C) 2002 Elsevier Science Inc. All rights reserved.

Keywords: Alzheimer's disease; Apolipoprotein; Apoptosis; BDNF; Caloric restriction; Chaperone; Folic acid; Parkinson's disease; Telomerase

\section{Introduction}

Many persons live for nine or more decades and enjoy a well-functioning brain until the very end of life. We therefore know what the brain is capable of and, accordingly, a major goal of research in the area of the neurobiology of aging should be to identify ways to facilitate successful brain aging in everyone. Studies of brains of the oldest old have provided evidence for stability as well as plasticity in successful brain aging. In many brain regions there is very little or no decrease in numbers of neurons, while in some brain regions neuronal loss may occur [67]. Nerve cell loss during aging may be compensated by expansion of dendritic arbors and increased synaptogenesis in the remaining neurons [4].

${ }^{*}$ Corresponding author. Tel.: +1-410-558-8463; fax: +1-410-558-8465.

E-mail address: mattsonm@grc.nia.nih.gov (M.P. Mattson).
In addition, it is thought that many neurons remain in the brain for a lifetime, although in some brain regions such as the olfactory bulb and dentate gyrus of the hippocampus, there is clearly a continual replacement of neurons from a pool of progenitor (stem) cells [30,101]. This regenerative capacity of brain may persist throughout the life-span.

While the brain can age successfully, its cells may face considerable adversity during the journey (Fig. 1). Increased oxidative stress (oxyradical production) and accumulation of oxidatively damaged molecules (proteins, nucleic acids and lipids) promote dysfunction of various metabolic and signaling pathways [62]. Neurons may also face energy deficits as the result of alterations in the cerebral vasculature and in mitochondrial function [42]. General, as well as specific, mechanisms of cellular signal transduction are altered during brain aging. Examples of widely used signaling mechanisms affected by aging include protein phosphorylation 


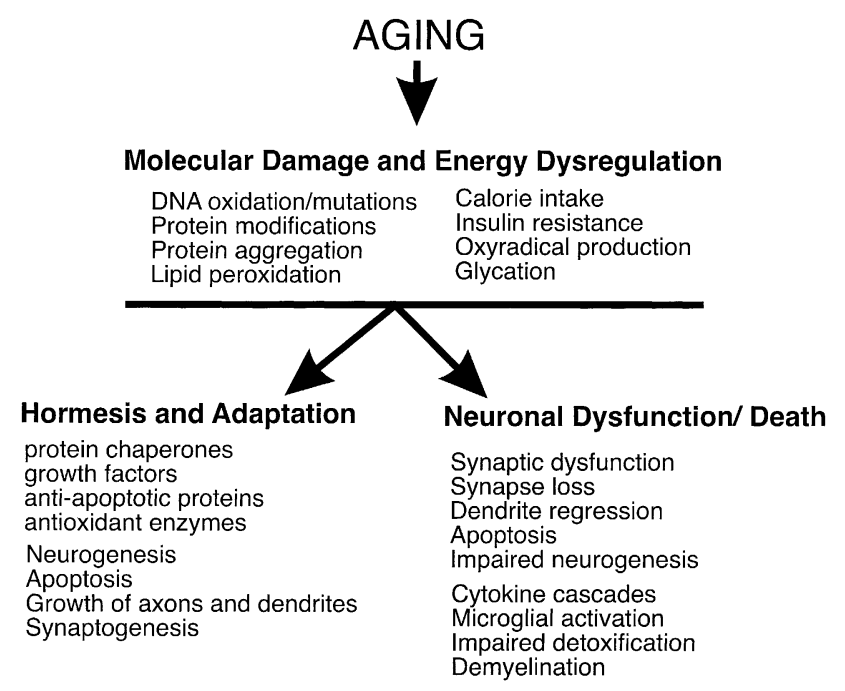

Fig. 1. With advancing age there is a progressive accumulation of damaged molecules and impaired energy metabolism in brain cells. In successful brain aging, the neurons and glial cells adapt to the adversities of aging by increasing their ability to cope with stress, and by compensating for lost or damaged cells by producing new brain cells and remodeling neuronal circuits (hormesis and adaptation). In unsuccessful aging, molecular damage to neurons and inflammatory processes result in synaptic dysfunction and neuronal degeneration and death, without replacement of the lost neurons.

(alterations in kinases and phosphatases) [50], cellular calcium homeostasis [77], protein folding and proteolysis [61], and gene transcription [64]. Among neurotransmitter systems, dopaminergic signaling appears to be consistently altered during aging with a progressive decrease in signaling via the D2 subtype of receptor [104]. These kinds of alterations that occur during normal aging likely set the stage for catastrophic neurodegenerative disorders that may be triggered by particular genetic predispositions or environmental factors.

Studies of embryonic and early postnatal development, and of synaptic plasticity in the young adult, have made a major contribution to our current understanding of the molecular and cellular mechanisms that determine whether brain aging occurs successfully or manifests dysfunction or disease. This is because the same intercellular signals and intracellular transduction pathways that regulate neurite outgrowth, synaptogenesis and cell survival during development are also operative throughout life. Although new signaling systems continue to be discovered, several classes of signaling molecules have emerged with neurotrophic factors, neurotransmitters, cytokines and steroids being particularly important in brain aging. Neurotrophic factors such as neurotrophins (brain-derived neurotrophic factor (BDNF), nerve growth factor (NGF), neurotrophin-3 (NT-3) and neurotrophin-4 (NT-4)), fibroblast growth factors, glial cell line-derived neurotrophic factor (GDNF) and ciliary neurotrophic factor (CNTF) have been shown to promote the survival of specific populations of brain neurons under experimental conditions relevant to brain aging and neurodegenerative disorders [81]. In addition to their roles as mediators of synaptic transmission, neurotransmitters such as glutamate, acetylcholine and dopamine also play important roles in regulating the formation of neuronal circuits during development and in influencing the neurodegenerative process in brain disorders of aging [77]. The status of such neurotransmitter, trophic factor and cytokine signaling systems is likely to have a major influence the outcome of brain aging.

\section{Hazards encountered by cells in the aging brain and their possible consequences}

As is the case in other organ systems, cells in the brain encounter a cumulative burden of oxidative and metabolic stress that may be a universal feature of the aging process. Fingerprints of increased oxidative stress during brain aging can be found on each of the major classes of cellular molecules including proteins, nucleic acids and lipids (Fig. 1). Oxidative modifications of proteins documented in neurons during aging include carbonyl formation $[10,12,21]$, covalent modification of cysteine, lysine and histidine residues by the lipid peroxidation product 4-hydroxynonenal [98], nitration of proteins on tyrosine residues [110] and glycation [96]. A common oxidative modification of DNA observed during brain aging is the formation of 8-hydroxydeoxyguanosine [111]. Increased lipid peroxidation during brain aging is manifest in the accumulation of lipid peroxidation products in neurons [83]. Each of the modifications of proteins, nucleic acids and lipids just described are greatly exacerbated in neurodegenerative disorders such as AD and Parkinson's disease, consistent with a major role for oxidative stress of aging in the pathogenesis of those disorders [76]. Analyses of experimental animal and cell culture models of age-related neurodegenerative disorders such as AD and Parkinson's disease and stroke have provided insight into the mechanisms that result in increased oxidative stress and damage to proteins, nucleic acids and membrane lipids. In Alzheimer's disease (AD), altered proteolytic processing of the $\beta$-amyloid precursor protein (APP) results in increased production of a long (42 amino acid) form of amyloid $\beta$-peptide which has a propensity to self-aggregate and form insoluble plaques in the brain [79]. During the process of aggregation, amyloid $\beta$-peptide generates reactive oxygen species that can induce membrane lipid peroxidation. The lipid peroxidation results in impairment of the function of membrane ion transport and glucose transport proteins which, in turn, leads to a disruption of neuronal ion homeostasis and energy metabolism [79]. These actions of amyloid $\beta$-peptide can cause dysfunction of synapses and can trigger a cell death cascade called apoptosis [23,85]. Degeneration of dopaminergic neurons in the substantia nigra and striatum of Parkinson's patients may be triggered by mitochondrial impairment 
and increased oxidative stress resulting from aging and exacerbated by environmental toxins such as pesticides and iron [48]. In the most common late-onset form of $\mathrm{AD}$ and Parkinson's disease the neurodegenerative cascade is most likely promoted by environmental factors (see section on environmental factors) that result in increased oxidative and metabolic stress. However, there are more rare inherited forms of these diseases in which disease onset occurs at an early age (30-60 years of age); a few of the genetic defects have been identified including mutations in APP and presenilins that cause $\mathrm{AD}[36,79]$, and mutations in $\alpha$-synuclein and parkin that cause Parkinson's disease [55,100].

Although some oxidative modifications of molecules in cells may serve adaptive signaling roles (e.g. S-nitrosylation of proteins; [41]), most such modifications impair the function of the modified molecule and can trigger cell death cascades. Studies of patients and experimental models of neurodegenerative disorders have revealed several specific examples of oxyradical-mediated dysfunction of regulatory proteins in neurons and glial cells. The membrane lipid peroxidation associated with amyloid deposition in AD results in impairment of the function of the plasma membrane $\mathrm{Na}^{+} / \mathrm{K}^{+}$- and $\mathrm{Ca}^{2+}$-ATPases [73,74], the neuronal glucose transporter GLUT3 [75], the astrocyte glutamate transporter EAA1 [52]. The coupling of neurotransmitter receptors to GTP-binding proteins, including muscarinic acetylcholine receptors and metabotropic glutamate receptors, is impaired by oxidative stress $[7,53]$. Oxidative modification of DNA can result in single- and double-strand breaks which, under conditions of an inadequate DNA repair response, can trigger an apoptotic cell death program involving the tumor suppressor protein $\mathrm{p} 53$, pro-apoptotic Bcl-2 family members such as Bax, and one or more cysteine proteases of the caspase family [95].

\section{Genetic and environmental factors in brain aging and neurodegenerative disorders}

An increasing number of genetic and environmental factors are being identified that can render neurons vulnerable to the aging process. An understanding of how such causal or predisposing risk factors promote neuronal dysfunction and/or death is critical for developing approaches to preserve functional neuronal circuits. We will therefore describe several prominent genetic aberrancies and environmental factors that either cause or increase risk of specific neurodegenerative disorders of aging. AD can be caused by mutations in the genes encoding the APP, presenilin-1 or -2 . Each of these mutations results in an increased production of amyloid $\beta$-peptide. Interestingly, the APP and presenilin mutations also decrease levels of a secreted form of APP that has been shown to promote synaptic plasticity (learning and memory) and survival of neurons $[29,46]$. At the heart of the mechanism whereby the APP and presenilin mutations promote synaptic dysfunction and neuronal degeneration is perturbed cellular calcium homeostasis $[36,79,85]$. In the case of APP mutations, the alterations in calcium homeostasis are the consequence of increased amyloid $\beta$-peptide production and decreased secreted APP production [79]. In the case of presenilin mutations, a primary defect in endoplasmic reticulum calcium regulation has been established $[36,85]$. The mutant presenilin-1 protein acquires an adverse property that results in an overfilling of endoplasmic reticulum calcium stores and an abnormality in capacitive calcium entry.

Abnormalities in synaptic transmission may be a major consequence of mutations in the $\alpha$-synuclein gene that cause familial Parkinson's disease. Mice lacking $\alpha$-synuclein exhibit a reduction in striatal dopamine levels, an attenuation of the locomotor response to amphetamine, and enhanced dopamine release from nigrostriatal terminals upon paired stimuli suggesting that $\alpha$-synuclein is an activity-dependent regulator of dopamine release [1]. It remains to be established if $\alpha$-synuclein mutations that cause Parkinson's disease result in similar abnormalities in dopaminergic neurotransmission, or if they result from a gain-of-function of the mutant protein. Huntington's disease is an age-related neurodegenerative disorder caused by trinucleotide expansions of the huntingtin gene resulting in a huntingtin protein with long stretches of polyglutamine repeats. Studies of transgenic mice and cultured neurons expressing mutant huntingtin suggest that the mutant protein may form abnormal aggregates, promote mitochondrial dysfunction and activate apoptotic biochemical cascades involving caspases [116]. Genetic factors that specifically increase risk of stroke are not well understood, whereas genes involved in lipoprotein metabolism that affect risk of cardiovascular disease similarly affect risk of stroke. However, the discovery that mutations in Notch-3 can cause a syndrome characterized by strokes is providing new insight into signaling pathways that influence cerebrovascular health during aging [51].

Genetic factors that increase risk of age-related neurodegenerative disorders are also being discovered, with one prominent example being apolipoprotein E polymorphisms. There are three isoforms of apolipoprotein E [2-4]; individuals that inherit the $\mathrm{E} 4$ allele are at increased risk of $\mathrm{AD}$. Although the molecular basis for this effect of apolipoprotein $\mathrm{E}$ genotype remains to be fully understood, experimental findings suggest that the E2 and E3 isoforms exhibit an antioxidant activity not possessed by the E4 isoform [99]. Other genetic polymorphisms have been reported to affect risk of $\mathrm{AD}$ including those in the genes encoding alpha2-macroglobulin, an apolipoprotein receptor and angiotensin converting enzyme. However, in the latter three cases many other studies have not confirmed the associations [102]. Numerous reports of associations of genetic polymorphisms with Parkinson's disease have appeared including those in the genes encoding cytochrome p450 enzymes, $N$-acetyltransferase 2 , monoamine oxidase-B and glutathione transferase; some of these remain viable candidates [13,114]. Additional genetic predisposition factors for 
these and other age-related neurodegenerative disorders will surely be identified.

The identification of gene mutations that cause age-related neurodegenerative disorders has led to the development of animal and cell culture models that have allowed rapid progress in understanding the cellular and molecular cascades responsible for neuronal degeneration and to novel preventative and therapeutic strategies. For example, the phenotypes of APP mutant mice and presenilin mutant mice provide strong evidence that these mutations result in altered APP processing and perturbed cellular calcium homeostasis, respectively [31,36]. An excellent model of amyotrophic lateral sclerosis (ALS) resulted from the identification of mutations in the $\mathrm{Cu} / \mathrm{Zn}$-SOD gene as causing familial ALS. Transgenic mice expressing mutant human $\mathrm{Cu} / \mathrm{Zn}$-SOD exhibit a phenotype remarkably similar to human patients, and these mice are now routinely being used to screen compounds to determine their ability to delay disease onset and/or progression [70].

Other studies have identified environmental factors that can increase risk of one or more neurodegenerative disorders. Epidemiological studies have provided evidence that individuals with a higher level of education are at reduced risk for AD [24]. Studies of dietary links to Parkinson's disease and $\mathrm{AD}$ suggest that individuals with a low calorie intake are at reduced risk [66,91], while those with a low level of folic acid in their diets are at increased risk $[15,60]$. Head trauma may also increase risk of AD and Parkinson's disease [71,119]. Exposure to environmental toxins such as the pesticide rotenone may increase risk of Parkinson's disease [5]. Similar to atherosclerotic heart disease, overeating, a high fat diet, smoking, folic acid deficiency and a sedentary lifestyle are risk factors for stroke [22]. Studies in animals models of AD and Parkinson's disease and stroke have generally supported the epidemiological data and established possible cause-effect relationships between specific environmental factors and neuronal vulnerability. For example, folate deficiency and elevated homocysteine levels can endanger neurons $[20,57,58]$, and caloric restriction can protect neurons $[8,18,124]$ in models relevant to $\mathrm{AD}$ and Parkinson's disease and stroke. Thus, data suggest that the probability of successful brain aging can be increased by reducing environmental risk factors.

\section{Successful brain aging}

Promoting the maintenance of cognitive, emotive, motor and sensory functions throughout the life-span (successful brain aging) should be considered as the goal of scientists in the broad field of the neurobiology of aging. This might be accomplished by avoiding genetic and environmental factors that facilitate neuronal dysfunction and death, or by enhancing the ability of neurons to adapt to the aging process. Rapid progress has been made in identifying cellular signaling mechanisms that promote cell survival, neurite growth and/or synapse formation/plasticity. A better understanding of these signaling pathways may reveal ways of promoting successful brain aging.

\section{Neuroprotective mechanisms}

Discovery of the cellular and molecular mechanisms that promote neuronal survival and plasticity has been a major focus of research in many laboratories during the past decade. Two major classes of intercellular signaling proteins that are firmly established as regulators of neuronal survival and synaptic plasticity are neurotrophic factors and cytokines. Cell culture and in vivo models relevant to the pathogenesis of age-related neurodegenerative disorders have identified many different neuroprotective factors with the following being prominent examples: basic fibroblast growth factor (bFGF), NGF, BDNF, NT-4, transforming growth factor- $\beta$ (TGF- $\beta$ ), tumor necrosis factor (TNF) and GDNF. One or more of these factors can protect one or more populations of brain neurons against excitotoxic, oxidative and metabolic insults in models of stroke, AD, Parkinson's and Huntington's disease [81]. In addition, signaling via cell adhesion proteins such as integrins is increasingly recognized as playing important roles in modulating neuronal survival [32]. In general, the mechanism whereby the growth factors, cytokines and integrin signaling promote neuronal survival is by inducing the expression of genes that encode proteins that suppress oxidative stress, stabilize cellular calcium homeostasis and block apoptotic biochemical cascades (Fig. 2). For example, bFGF, BDNF, TNF and NGF can increase the production of one or more antioxidant enzymes $(\mathrm{Cu} / \mathrm{Zn}-\mathrm{SOD}, \mathrm{Mn}-\mathrm{SOD}$, glutathione peroxidase and catalase) in hippocampal neurons $[78,80,82]$. By activating kinases such as mitogen-activated protein (MAP) kinase and protein kinase $\mathrm{C}$, and transcription factors such as NF- $\mathrm{\kappa B}$ and CREB, neurotrophic factors and cytokines can modulate the expression and/or activity of subunits of glutamate receptors and voltage-dependent calcium channels in ways that promote neuronal survival and synaptic plasticity $[80,87,120]$. Two other classes of neuroprotective proteins that are upregulated by growth factors, cytokines and cell adhesion molecules are antiapoptotic Bcl-2 family members [9] and inhibitor of apoptosis proteins [122].

In addition to antioxidant enzymes and antiapoptotic proteins such as Bcl-2 and IAPs, neurons express several so-called chaperone proteins that exert prominent neuroprotective actions. Chaperone proteins interact with many different proteins in cells and function to ensure their proper folding on the one hand, and degradation of damaged proteins, on the other hand [27,34]. Two chaperone proteins that have been shown to protect neurons against injury and death in experimental models of neurodegenerative disorders are heat-shock protein-70 (HSP-70) and glucose-regulated protein-78 (GRP-78) [68,125]. Expression of such chaperone proteins may be increased during 


\section{Transcription-Dependent}

Life

BDNF - trkB - PI3K - Akt - TF - Bcl2

SAPP $\alpha$ - APPR - cGMP - PKG - NF-KB - IAP

TNFa - TNFR - IKK - NF-KB - MnSOD

Laminin - Integrin - PI3K - Akt - TF - Bcl2

\section{Death}

Glutamate - NMDAR - Calcium - Par4 - decr NF-kB - apoptosis Amyloid $\beta$-peptide - Oxyradicals - cJun - apoptotic cascade

Homocysteine - DNA damage - p53 - Bax - Mtoch - Caspases

\section{Transcription-Independent}

\section{Life}

sAPP $\alpha$ - APPR - cGMP - PKG - PPase - K channel

Glutamate - NMDAR - calcium - gelsolin - actin - decr NMDAR

bFGF - R - PK - ? - glucose transport

Death

Iron - Oxyradicals - Par4 - Mitoch - apoptosis

MPTP - MPP+ - Oxyradicals - Mitoch - apoptosis

Ischemia - energy failure - necrosis and apoptosis

Fig. 2. Examples of cellular signaling pathways that modulate neuronal plasticity and survival during aging. BDNF: brain-derived neurotrophic factor; trkB: high affinity BDNF receptor; PI3K: phosphatidylinositol-3-kinase; Akt: Akt kinase; TF: transcription factor; sAPP: secreted form of amyloid precursor protein; APPR: amyloid precursor protein receptor; cGMP: cyclic guanosine monophosphate; PKG: protein lunase G; IAP: inhibitor of apoptosis protein; TNF: tumor necrosis factor; IKK: I kappa B lunase; Mn-SOD: manganese superoxide dismutase; NMDAR: $N$-methyl-D-aspartate receptor; Par-4: prostate apoptosis response-4; R: receptor; PK: protein kinase; MPTP: 1-methyl-4-phenyl-1,2,3,6tetrahydropyridine; $\mathrm{MPP}+$ : reactive form of MPTP.

aging as protective response $[37,64,124]$. It is particularly interesting that caloric restriction, a dietary manipulation that increases life-span and brain health-span [26,121], also increases expression of chaperone proteins in neurons of rats and mice $[18,124]$.

The function of neuroprotective signaling pathways, chaperone proteins and antiapoptotic proteins in synaptic terminals may be particularly important for promoting synaptic plasticity and preventing synapse loss and neuronal death during aging $[35,84]$. Synapses are very likely to be the sites where the impact of aging is first exerted upon the neuron and it is therefore of great importance to understand how genes and environment affect synaptic homeostasis. Table 1 provides some examples of studies documenting both beneficial and detrimental effects of specific genetic and environmental factors on synapses.

\section{Neurorestorative mechanisms}

Two conclusions that have arisen from work done in many different laboratories during the past 10 years are that regeneration/compensation can occur in the adult brain, and that the brain contains populations of stem cells or neural progenitor cells (NPC) that are capable of dividing and then differentiating into neurons or glia [101]. When axons of neurons in the brain are damaged, sprouting of new axonal processes occurs. However, in contrast to the peripheral nervous system the brain contains a number of inhibitory signals that often prevent successful reinnervation of target cells [107]. In addition, when synaptogenesis does occur it may not replace lost function because of the high degree of specificity of neuronal connections in the brain and the fact that many brain functions rely on "memories" based on the past history of synaptic activity. Various neurotrophic factors and cytokines are involved in the modulation of neurite outgrowth and synaptic recovery after brain injury $[47,81]$.

One of the most exciting and rapidly growing areas in the field of neuroscience is stem cell biology. The adult brain contains two major populations of pluripotent progenitor cells, one in the subventricular zone and the other in the subgranular layer of the dentate gyrus of the hippocampus [30]. These NPC cells can give rise to either neurons or astrocytes, and there is increasing evidence that many of the newly-generated cells survive and become functional, although some may undergo programmed cell death. NPC can be labeled by giving animals the thymidine analog

Table 1

Examples of aging-relevant genes and environmental factors that affect synaptic homeostasis in positive or negative ways

\begin{tabular}{|c|c|c|}
\hline & Effect on synapses & References \\
\hline \multicolumn{3}{|l|}{ Genes } \\
\hline $\operatorname{APP}(\mathrm{sAPP} \alpha)$ & $\begin{array}{l}\text { Enhanced plasticity, glucose transport, glutamate transport } \\
\text { Reduced oxidative stress, improved mitochondrial function }\end{array}$ & {$[29,84]$} \\
\hline APP mutations & Impaired plasticity, disturbed calcium and oxyradical metabolism & [79] \\
\hline Presenilin-1 mutations & Impaired plasticity, disturbed calcium and oxyradical metabolism & [36] \\
\hline$\alpha$-Synuclein & Regulate dopamine release & {$[1]$} \\
\hline$\alpha$-Synuclein mutations & Perturbed dopamine release & {$[106]$} \\
\hline \multicolumn{3}{|l|}{ Environment } \\
\hline Dietary restriction & $\begin{array}{l}\text { Enhanced plasticity, glucose transport, glutamate transport } \\
\text { Reduced oxidative stress, improved mitochondrial function }\end{array}$ & {$[19,37]$} \\
\hline Cognitive activity & Enhanced plasticity & {$[43,54,105]$} \\
\hline Physical activity & Enhanced plasticity & [17] \\
\hline Trauma & Impaired plasticity and mitochondrial function & [2] \\
\hline Chronic stress & Impaired plasticity & [112] \\
\hline
\end{tabular}



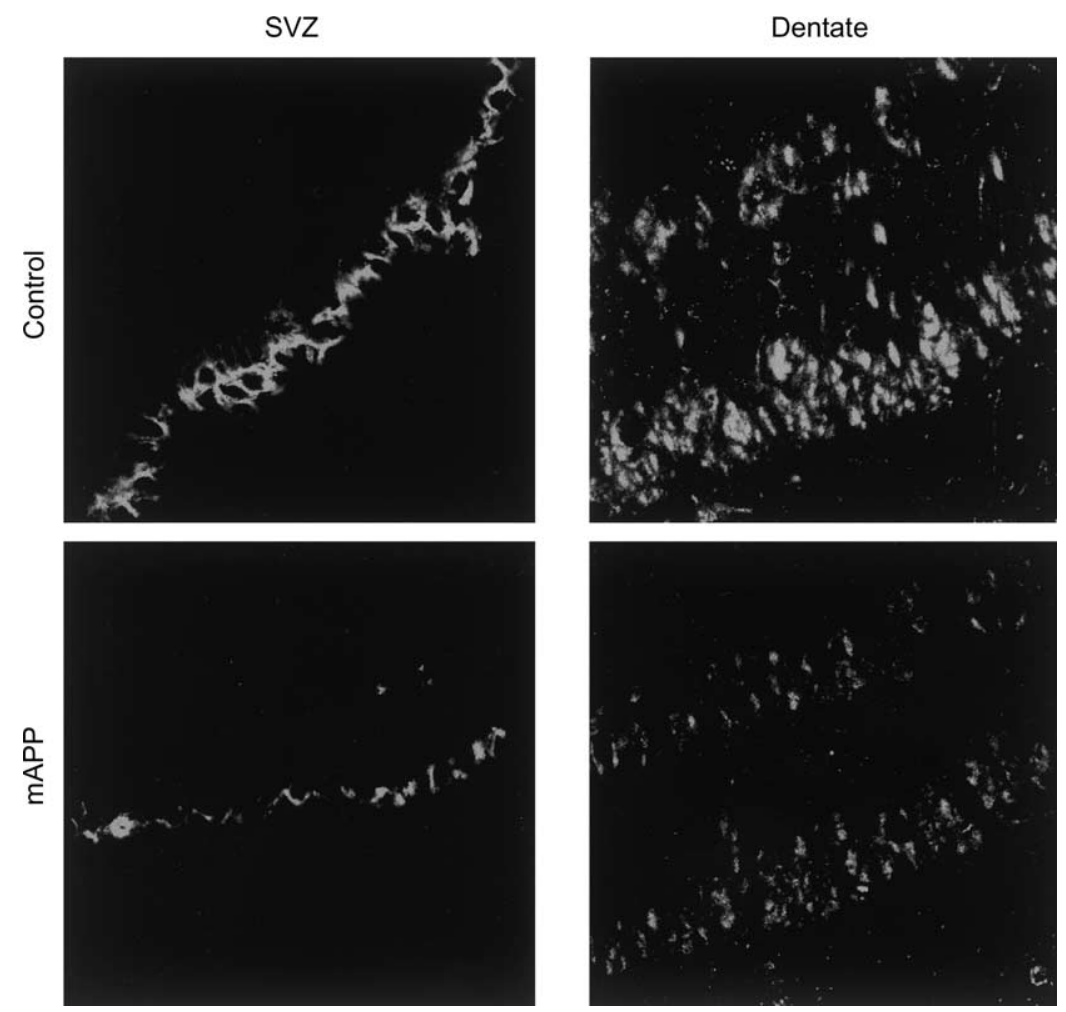

Fig. 3. Production of new dentate granule neurons is decreased in an APP mutant mouse model of Alzheimer's disease. Confocal images showing immunoreactivity with an antibody against a protein (E-NCAM) expressed in neuron-restricted progenitor cells and newly differentiated neurons in the subventricular zone (SVZ), and in the dentate gyrus of the hippocampus in non-transgenic (control) and APP mutant transgenic mice. Note that numbers of newly-generated neuronal cells were decreased in APP mutant mouse.

bromodeoxyuridine (BrdU), and the phenotype of their differentiated progeny can be determined by double-labeling using antibodies against neuronal (e.g. pNCAM or $\beta 3$-tubulin) or astrocyte (GFAP) markers (Fig. 3). Considerable progress has been made in identifying signals that control the proliferation, differentiation and survival of NPC $[30,101]$. For example, bFGF and epidermal growth factor (EGF) can maintain NPC in a proliferative state, BDNF and neurotrophin-3 can promote their differentiation and/or survival, and bone morphogenetic protein can induce NPC to become astrocytes [12,92]. Other prominent signaling mechanisms that control NPC cell fate include Notch [115], neurogenin [113] and the secreted form of APP (Fig. 4). Brain injury is a potent stimulus for neurogenesis [65] and this effect is likely mediated by the trophic factors and cytokines induced by cell injury $[11,80,81]$.

Telomerase is a reverse transcriptase that adds a six-base DNA repeat onto the ends of chromosomes (telomeres) and thereby maintains the integrity to chromosomes during successive rounds of cells division. Telomerase may play a major role in the aging process by virtue of its absence from most somatic cells in the adult [88]. However, telomerase is present in brain cells during development, where it is thought to play a role maintenance of NPC in a proliferative state, and in promoting survival of NPC and their neuronal and glial progeny $[28,56]$. Telomerase is also present in NPC in the adult brain where its expression may be influenced by brain injury and other environmental factors. Because the catalytic subunit of telomerase (TERT) can prevent apoptosis of cultured neurons in experimental models relevant to $\mathrm{AD}$ and stroke $[28,126]$, it is has been proposed that induction of TERT expression in neurons or NPC in the adult brain may increase resistance to age-related neurodegenerative disorders [89]. DNA damage is implicated in age-related neurodegenerative processes and increasing data suggest that telomerase may play an important role in DNA damage responses. For example, telomerase can protect embryonic neurons against $\mathrm{p} 53$-mediated apoptosis induced by DNA-damaging agents [69]. Reducing DNA damage and/or enhancing DNA repair in neurons would be expected to extend brain health-span.

Neurogenesis may decrease during normal aging [59], and this effect of aging may be counteracted by many of the same environmental conditions that promote successful brain aging. Thus, neurogenesis in the dentate gyrus can be increased by environmental enrichment [54,97] and physical exercise [117]. Importantly, dietary restriction can induce neurogenesis in the brain [63]. The latter study showed that BDNF levels are increased in rats maintained on dietary restriction, and that the major effect of dietary restriction on NPC is to promote the survival of their progeny. More recently, it was shown that many of 


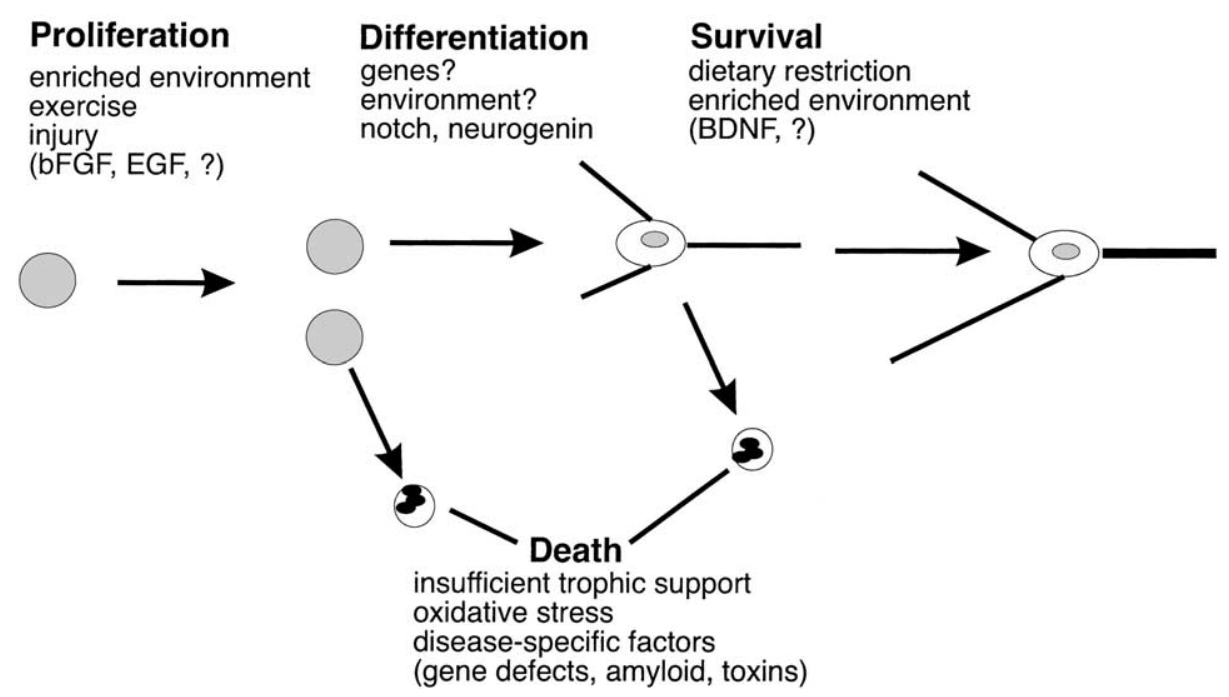

Fig. 4. The process of neurogenesis involves proliferation of neural precursor cells, differentiation into neurons and long-term survival of the newly-generated neurons. See text for description.

the newly-generated cells become dentate granule neurons (Fig. 3).

When taken together with the fact that learning and memory is preserved in aging rodents maintained on dietary restriction [44], and that suppression of NPC proliferation can impair learning and memory [109], it is possible that dietary restriction promotes maintenance of cognitive function during aging by enhancing neurogenesis (Fig. 1).

Because no specific molecular markers of NPC have been established, and because NPC cannot be labeled by the usual BrdU method in clinical studies of humans, it is not known whether abnormalities in neurogenesis contribute to the pathogenesis of age-related neurodegenerative disorders. However, recent studies of experimental models of AD have shown that amyloid $\beta$-peptide can impair neurogenesis [40]. Both the proliferation and survival of NPC in the dentate gyrus of the hippocampus are reduced in APP mutant mice. Infusion of amyloid $\beta$-peptide into the lateral ventricle of adult mice impairs neurogenesis of NPC in the subventricular region. Moreover, exposure of cultured human NPC to amyloid $\beta$-peptide impairs their proliferation and differentiation and can induce apoptosis [40]. These experimental findings suggest that adverse effects of amyloid $\beta$-peptide on NPC may contribute to depletion of neurons and cognitive impairment in AD. Although it is not known whether a failure of neurogenesis contributes to the pathogenesis of Parkinson's disease, numerous studies in rodents, non-human primates and humans suggest that functional recovery can occur following transplantation of NPC or mobilization of endogenous NPC [6]. The development of methods for identifying NPC and their recent progeny in postmortem brain tissue sections from human patients would greatly facilitate our understanding of the relative contributions of neuronal degeneration and impaired neurogenesis to neurodegenerative disorders.
The implications of NPC for facilitating successful brain aging and treating age-related neurodegenerative disorders are quite profound. It seems possible to either mobilize endogenous NPC in the brain, or to introduce exogenous NPC or multipotent stem cells (e.g. embryonic stem cells), so as to replace dysfunctional or dead neurons and glia. As described above, three different behavioral modifications have been shown to enhance neurogenesis (dietary restriction, and increased cognitive and physical activities). In addition, pharmacological approaches for mobilizing NPC are being developed. For example, it has been shown that antidepressant drugs such as serotonin transport inhibitors can increase production of BDNF and stimulate neurogenesis $[3,72]$. There have already been reports of improved functional outcome following NPC transplantation in models of traumatic CNS injury [93], demyelinating disorders [123] and Parkinson's disease [6]. Particularly intriguing are reports suggesting that stem cells in other organs of the body, including bone marrow, are capable of forming neurons and glial cells [94]. A major clinical hurdle in inter-individual transplantations is immune attack on the transplanted cells; this could be avoided by using a person's own stem cells for transplantation. Embyronic stem cells may also prove valuable in treating various neurodegenerative disorders because of their multipotent properties and their reduced reactivity towards immune cells.

\section{Prescription for successful brain aging}

Brain disorders of aging have recently become leading causes of disability and death, due to advances in the prevention and treatment of cardiovascular disease and cancers which have allowed many more people to live beyond the age of 70. Accordingly, research efforts on neurodegenerative 
disorders have rapidly expanded in the past decade and those efforts have led to the kinds of major advances described above. We are now at a point in time where knowledge of the genetic and environmental factors linked to unsuccessful brain aging, and their cellular and molecular consequences, can be used to make recommendations to the general population. In the two paragraphs below, we provide short lists of approaches for the prevention and treatment of neurodegenerative disorders that are likely to have a major impact.

\subsection{Ensuring the future}

Prevention is the road of choice, the road to a healthy brain and to avoidance of pain and suffering. While, we cannot yet readily change our genome to weed out the bad genes, we can take steps to counteract bad genes and the progressive molecular and cellular attrition of aging. Several prominent risk factors for major age-related diseases such as cardiovascular disease, type 2 diabetes and cancers are also risk factors for neurodegenerative disorders. These include a high calorie diet, vitamin insufficiencies (particularly folic acid and antioxidants) and a sedentary lifestyle. In addition, using the brain can extend its health-span. Links between high cholesterol levels and AD [25], pesticides and Parkinson's disease [5] and dietary toxins and ALS [103] have been suggested. Thus, steps can be taken immediately to reduce one's risk for brain disorders of aging. As with other age-related diseases the single most effective means of reducing risk for neurodegenerative disorder is to reduce caloric intake during adult life [90]. New dietary and behavioral approaches for promoting healthy brain aging will undoubtedly emerge from ongoing research. There are also likely to be pharmacological interventions to retard brain aging. Antioxidants such as Vitamin E, coenzyme Q10, lipoic acid and ginko extract, and supplements such as creatine that enhance cellular energy maintenance, may provide some degree of protection $[39,86,108,118]$. We have been evaluating dietary supplements that mimic the physiological effects of caloric restriction for their ability to enhance resistance of neurons to age-related disease $[18,38,124]$. Suppressing apoptosis using agents that target key proteins in the cell death process, such as p53 and caspases, is another potentially effective strategy [16]. It has also been suggested that cholesterol-lowering stains may protect the brain against age-related disease via actions on the vasculature or directly on neurons [49]. In addition to preventative strategies that affect pathways of neuronal degeneration or neuroprotection that are shared among age-related neurodegenerative disorders, novel disease-specific approaches are also being developed. In the case of $\mathrm{AD}$, for example, drugs that inhibit $\beta$ - and $\gamma$-secretases and thereby reduce amyloid $\beta$-peptide production are being developed [14], as are amyloid vaccine-based approaches [45].

\subsection{Undoing the past}

Finding cures for age-related brain dysfunction and disease is a worthy, but elusive and frustrating, goal. Once patients with AD, Parkinson's and Huntington's diseases and stroke become symptomatic, considerable damage to neuronal circuits has already occurred. Treatment strategies are therefore focused on halting further neuronal degeneration and promoting re-establishment of neuronal circuits. There is increasing optimism that this daunting challenge can be met. First, emerging data suggest that the extent of neuronal death in Parkinson's and Alzheimer's patients during the early period of the diseases may not be as great as initially thought; instead, many neurons may be dysfunctional and capable of revival $[33,45]$. Second, neural stem cells may be capable of replacing lost neurons [30,101], Third, it may be possible to manipulate cell adhesion and signaling pathways in ways that enhance neurite outgrowth and synaptogenesis [107]. Administration of neurotrophic factors, mobilization or transplantation of neural stem cells, and drugs that enhance synaptic transmission are currently in clinical trials. Combinations of the latter approaches and the same measures used for prevention (anti oxidants, caloric restriction, behavioral therapy, etc.) will likely emerge as the most efficacious treatments of age-related neurodegenerative disorders.

\section{References}

[1] Abeliovich A, Schmitz Y, Farinas I, Choi-Lundberg D, Ho WH, Castillo PE, et al. Mice lacking alpha-synuclein display functional deficits in the nigrostriatal dopamine system. Neuron 2000;25: 239-52.

[2] Albensi BC, Sullivan PG, Thompson MB, Scheff SW, Mattson MP. Cyclosporin ameliorates traumatic brain injury-induced alterations of hippocampal synaptic plasticity. Exp Neurol 2000;162:385-9.

[3] Altar CA. Neurotrophins and depression. Trends Pharmacol Sci 1999;20:59-61.

[4] Bertoni-Freddari C, Fattoretti P, Paoloni R, Caselli U, Galeazzi L, Meier-Ruge W. Synaptic structural dynamics and aging. Gerontology 1996;42:170-80.

[5] Betarbet R, Sherer TB, MacKenzie G, Garcia-Osuna M, Panov AV, Greenamyre JT. Chronic systemic pesticide exposure reproduces features of Parkinson's disease. Nat Neurosci 2000;3:1301-6.

[6] Bjorklund A. Cell replacement strategies for neurodegenerative disorders. Novartis Found Symp 2000;231:7-15.

[7] Blanc EM, Kelly JF, Mark RJ, Mattson MP. 4-Hydroxynonenal, an aldehydic product of lipid peroxidation, impairs signal transduction associated with muscarinic acetyleholine and metabotropic glutamate receptors: possible action on $\mathrm{G} \alpha_{\mathrm{q} / 11}$. J Neurochem 1997;69:570-80.

[8] Bruce-Keller AJ, Umberger G, McFall R, Mattson MP. Food restriction reduces brain damage and improves behavioral outcome following excitotoxic and metabolic insults. Ann Neurol 1999;45: $8-15$.

[9] Bui NT, Livolsi A, Peyron JF, Prehn JH. Activation of nuclear factor kappa B and Bcl-x survival gene expression by nerve growth factor requires tyrosine phosphorylation of I kappa B alpha. J Cell Biol 2001;152:753-64.

[10] Butterfield DA, Howard BJ, Yatin S, Allen KL, Carney JM. Free radical oxidation of brain proteins in accelerated senescence and 
its modulation by $N$-tert-butyl-alpha-phenylnitrone. Proc Natl Acad Sci USA 1997;94:674-8.

[11] Caidwell MA, He X, Wilkie N, Pollack S, Marshall G, Wafford $\mathrm{KA}$, et al. Growth factors regulate the survival and fate of cells derived from human neurospheres. Nat Biotechnol 2001;19:475-9.

[12] Cakatay U, Telci A, Kayali R, Tekeli F, Akcay T, Sivas A. Relation of oxidative protein damage and nitrotyrosine levels in the aging rat brain. Exp Gerontol 2001;36:221-9.

[13] Checkoway H, Farin FM, Costa-Mallen P, Kirchner SC, Costa LG. Genetic polymorphisms in Parkinson's disease. Neurotoxicology 1998;19:635-43.

[14] Citron M. Secretases as targets for the treatment of Alzheimer's disease. Mol Med Today 2000;6:392-7.

[15] Clarke R, Smith AD, Jobst KA, Refsum H, Sutton L, Ueland PM. Folate, Vitamin B12, and serum total homocysteine levels in confirmed Alzheimer disease. Arch Neurol 1998;55:1449-55.

[16] Culmsee C, Zhu Z, Yu QS, Chan SL, Camandola S, Guo Z, et al. A synthetic inhibitor of p53 protects neurons against death induced by ischemic and excitotoxic insults, and amyloid $\beta$-peptide. J Neurochem 2001;77:220-8.

[17] Dobkin BH. Activity-dependent learning contributes to motor recovery. Ann Neurol 1998;44:158-60.

[18] Duan W, Mattson NW. Dietary restriction and 2-deoxyglucose administration improve behavioral outcome and reduce degeneration of dopaminergic neurons in models of Parkinson's disease. J Neurosci Res 1999;57:195-206.

[19] Duan W, Guo Z, Mattson MP. Brain-derived neurotrophic factor mediates an excitoprotective effect of dietary restriction in mice. $\mathbf{J}$ Neurochem 2001;76:619-26.

[20] Duan W, Ladenheim B, Cutler RG, Cadet JL, Mattson MP. Dietary folate deficiency and elevated homocysteine levels endanger dopaminergic neurons in models of Parkinson's disease. Ann Neurol, in press.

[21] Dubey A, Forster MJ, Lal H, Sohal RS. Effect of age and caloric intake on protein oxidation in different brain regions and on behavioral functions of the mouse. Arch Biochem Biophys 1996;333:189-97.

[22] Elkind MS, Sacco RL. Stroke risk factors and stroke prevention. Semin Neurol 1998;18:429-40.

[23] Estus S, Tucker HM, van Rooyen C, Wright S, Brigham EF, Wogulis $\mathrm{M}$, et al. Aggregated amyloid-beta protein induces cortical neuronal apoptosis and concomitant "apoptotic" pattern of gene induction. J Neurosci 1997;17:7736-45.

[24] Evans DA, Hebert LE, Beckett LA, Scherr PA, Albert MS, Chown $\mathrm{MJ}$, et al. Education and other measures of socioeconomic status and risk of incident Alzheimer disease in a defined population of older persons. Arch Neurol 1997;54:1399-405.

[25] Fassbender K, Simons M, Bergmann C, Stroick M, Lutjohann D, Keller P, et al. Simvastatin strongly reduces levels of Alzheimer's disease beta-amyloid peptides Abeta 42 and Abeta 40 in vitro and in vivo. Proc Natl Acad Sci USA 2001;98:5856-61.

[26] Finch CE, Morgan TE. Food restriction and brain aging. In: Mattson MP, Geddes JW, editors. The aging brain. Adv Cell Aging Gerontol 1997;2:279-97.

[27] Frydman J. Folding of newly translated proteins in vivo: the role of molecular chaperones. Ann Rev Biochem 2001;70:603-47.

[28] Fu W, Killen M, Culmsee C, Dhar S, Pandita TK, Mattson MP. The catalytic subunit of telomerase is expressed in developing brain neurons and serves a cell survival-promoting function. J Mol Neurosci 2000;14:3-15.

[29] Furukawa K, Barger SW, Blalock EM, Mattson MP. Activation of $\mathrm{K}+$ channels and suppression of neuronal activity by secreted beta-amyloid precursor protein. Nature 1996;379:74-8.

[30] Gage FH. Mammalian neural stem cells. Science 2000;287:1433-8.

[31] Games D, Adams D, Alessandrini R, Barbour R, Berthelette P, Blackwell C, et al. Alzheimer-type neuropathology in transgenic mice overexpressing $\mathrm{V} 717 \mathrm{~F}$ beta-amyloid precursor protein. Nature 1995;373:523-7.
[32] Gary DS, Mattson MP. Integrin signaling via the P13-kinase-Akt pathway increases neuronal resistance to glutamate-induced apoptosis. J Neurochem 2001;76:1485-96.

[33] Gash DM, Zhang Z, Gerhardt G. Neuroprotective and neurorestorative properties of GDNF. Ann Neurol 1998;44:S121-5.

[34] Gething MJ. Role and regulation of the ER chaperone BiP. Semin Cell Dev Biol 1999;10:465-72.

[35] Guo ZH, Mattson MP. Neurotrophic factors protect synaptic terminals against arnyloid- and oxidative stress-induced impairment of glucose transport, glutamate transport and mitochondrial function. Cerebral Cortex 1999;10:50-7.

[36] Guo Q, Fu W, Sopher BL, Miller MW, Ware CB, Martin GM, et al. Increased vulnerability of hippocampal neurons to excitotoxic necrosis in presenilin-1 mutant knock-in mice. Nat Med 1999;5:101-6.

[37] Guo Z, Ersoz A, Butterfield DA, Mattson MP. Beneficial effects of dietary restriction on cerebral cortical synaptic terminals: preservation of glucose transport and mitochondrial function after exposure to amyloid $\beta$-peptide and oxidative and metabolic insults. J Neurochem 2000;75:314-20.

[38] Guo Z, Lee J, Lane MA, Mattson MP. Iodoacetate protects hippocampal neurons against excitotoxic and oxidative injury: involvement of heat-shock proteins and Bcl-2. J Neurochem 2001;79:361-70.

[39] Gutzmann H, Hadler D. Sustained efficacy and safety of idebenone in the treatment of Alzheimer's disease: update on a 2-year double-blind multicentre study. J Neural Trans Suppl 1998;54: 301-10.

[40] Haughey NJ, Liu D, Nath A, Borchard AC, Mattson MP. Disruption of neurogenesis in the subventricular zone of adult mice, and in human cortical neuronal precursor cells in culture, by amyloid beta-peptide: implications for the pathogenesis of Alzheimer's disease. NeuroMolecular Med 2002;1:125-36.

[41] Hess DT, Matsumoto A, Nudelman R, Stamler JS. S-nitrosylation: spectrum and specificity. Nat Cell Biol 2001;3:E46-9.

[42] Hoyer S. Age-related changes in cerebral oxidative metabolism. Implications for drug therapy. Drugs Aging 1995;6:210-8.

[43] Ickes BR, Pham TM, Sanders LA, Albeck DS, Mohammed AH, Granholm AC. Long-term environmental enrichment leads to regional increases in neurotrophin levels in rat brain. Exp Neurol 2000;164:45-52.

[44] Ingram DK, Weindruch R, Spangler EL, Freeman JR, Walford RL. Dietary restriction benefits learning and motor performance of aged mice. J Gerontol 1987;42:78-81.

[45] Ingram DK. Vaccine development for Alzheimer's disease: a shot of good news. Trends Neurosci 2001;24:305-7.

[46] Ishida A, Furukawa K, Keller JN, Mattson MP. Secreted form of beta-amyloid precursor protein shifts the frequency dependency for induction of LTD, and enhances LTP in hippocampal slices. Neuroreport 1997;8:2133-7.

[47] Jankowsky JL, Pauerson PH. Cytokine and growth factor involvement in long-term potentiation. Mol Cell Neurosci 1999;14:273-86.

[48] Jenner P, Olanow CW. Understanding cell death in Parkinson's disease. Ann Neurol 1998;44:S72-84.

[49] Jick H, Zornberg GL, Jick SS, Seshadri S, Drachman DA. Statins and the risk of dementia. Lancet 2000;356:27-1631.

[50] Jin LW, Saitoh T. Changes in protein kinases in brain aging and Alzheimer's disease. Implications for drug therapy. Drugs Aging 1995;6:136-49.

[51] Kalimo H, Viitanen M, Amberla K, Juvonen V, Marttila R, Poyhonen M, et al. CADASIL: hereditary disease of arteries causing brain infarcts and dementia. Neuropathol Appl Neurobiol 1999;25:257-65.

[52] Keller TN, Pang Z, Geddes JW, Begley JG, Germeyer A, Waeg G, et al. Impairment of glucose and glutamate transport and induction of mitochondrial oxidative stress and dysfunction in synaptosomes by amyloid beta-peptide: role of the lipid peroxidation product 4-hydroxynonenal. J Neurochem 1997;69:273-84. 
[53] Kelly JF, Furukawa K, Barger SW, Rengen MR, Mark RJ, Blanc EM, et al. Amyloid beta-peptide disrupts carbachol-induced muscarinic cholinergic signal transduction in cortical neurons. Proc Natl Acad Sci USA 1996;93:6753-8.

[54] Kempermann G, Kuhn HG, Gage FH. More hippocampal neurons in adult mice living in an enriched environment. Nature 1997;386: 493-5.

[55] Kitada T, Asakawa S, Hattori N, Matsumine H, Yamamura Y, Minoshima S, et al. Mutations in the parkin gene cause autosomal recessive juvenile parkinsonism. Nature 1998;392:605-8.

[56] Klapper W, Shin T, Mattson MP. Differential regulation of telomerase activity and TERT expression during brain development in mice. J Neurosci Res 2001;64:252-60.

[57] Kruman I, Chan SL, Culmsee C, Kruman Y, Penix L, Mattson MP. Homocysteine elicits a DNA damage response in neurons resulting in apoptosis and hypersensitivity to excitotoxicity. J Neurosci 2000;20:6920-6.

[58] Kruman II, Kumaravel TS, Lohani A, Cutler RG, Pedersen WA, Kruman Y, Evans M, Mattson MP. Folic acid deficiency and homocysteine impair DNA repair and sensitize hippocampal neurons to death in experimental models of Alzheimer's disease. J Neurosci 2002;22:1752-62.

[59] Kuhn HG, Dickinson-Anson H, Gage FH. Neurogenesis in the dentate gyrus of the adult rat: age-related decrease of neuronal progenitor proliferation. J Neurosci 1996;16:2027-33.

[60] Kuhn W, Roebroek R, Blom H, van Oppenraaij D, Przuntek H, Kretschmer A, et al. Elevated plasma levels of homocysteine in Parkinson's disease. Eur Neurol 1998;40:225-7.

[61] Kumar VB, Franko MW, Farr SA, Armbrecht HJ, Morley JE. Identification of age-dependent changes in expression of senescence-accelerated mouse (SAMP8) hippocampal proteins by expression array analysis. Biochem Biophys Res Commun 2000;272:657-61.

[62] LeBel CP, Bondy SC. Oxidative damage and cerebral aging. Prog Neurobiol 1992;38:601-9.

[63] Lee J, Duan W, Long JM, Ingram DK, Mattson MP. Dietary restriction increases survival of newly-generated neural cells and induces BDNF expression in the dentate gyrus of rats. $\mathrm{J}$ Mol Neurosci 2000;15:99-108.

[64] Lee CK, Weindruch R, Prolla TA. Gene-expression profile of the ageing brain in mice. Nat Genet 2000;25:294-7.

[65] Liu J, Solway K, Messing RO, Sharp FR. Increased neurogenesis in the dentate gyrus after transient global ischemia in gerbils. J Neurosci 1998;18:7768-78.

[66] Logroscino G, Marder K, Cote L, Tang MX, Shea S, Mayeux R. Dietary lipids and antioxidants in Parkinson's disease: a population-based, case-control study. Ann Neurol 1996;39:89-94.

[67] Long JM, Mouton PR, Jucker M, Ingram DK. What counts in brain aging? Design-based stereological analysis of cell number. J Gerontol A Biol Sci Med Sci 1999;54:B407-17.

[68] Lowenstein DH, Chan PH, Miles MF. The stress protein response in cultured neurons: characterization and evidence for a protective role in excitotoxicity. Neuron 1991;7:1053-60.

[69] Lu C, Fu W, Mattson MP. Telomerase protects developing neurons against DNA damage-induced cell death. Dev Brain Res 2001;131:167-71.

[70] Ludoiph AC. Treatment of amyotrophic lateral sclerosis-what is the next step? J Neurol 2000;246:S13-8.

[71] Lye TC, Shores EA. Traumatic brain injury as a risk factor for Alzheimer's disease: a review. Neuropsychol Rev 2000;10:115-29.

[72] Malberg JE, Eisch AJ, Nestler EJ, Duman RS. Chronic antidepressant treatment increases neurogenesis in adult rat hippocampus. J Neurosci 2000;20:9104-10.

[73] Mark RJ, Hensley K, Butterfield DA, Mattson MP. Amyloid beta-peptide impairs ion-motive ATPase activities: evidence for a role in loss of neuronal $\mathrm{Ca}^{2+}$ homeostasis and cell death. J Neurosci 1995;15:6239-49.
[74] Mark RJ, Lovell MA, Markesbery WR, Uchida K, Mattson MP. A role for 4-hydroxynonenal, an aldehydic product of lipid peroxidation, in disruption of ion homeostasis and neuronal death induced by amyloid beta-peptide. J Neurochem 1997;68:255-64.

[75] Mark RJ, Pang Z, Geddes JW, Uchida K, Mattson MP. Amyloid beta-peptide impairs glucose transport in hippocampal and cortical neurons: involvement of membrane lipid peroxidation. J Neurosci 1997; 17:1046-54.

[76] Markesbery WR, Montine TJ, Lovell MA. Oxidative alterations in neurodegenerative diseases. In: Mattson MP, editor. Pathogenesis of neurodegenerative disorders. Totowa, NJ: Human Press Inc., 2001. p. 21-51.

[77] Mattson MP. Calcium as sculptor and destroyer of neural circuitry. Exp Gerontol 1992;27:29-49.

[78] Mattson MP, Lovell MA, Furukawa K, Markesbery WR. Neurotrophic factors attenuate glutamate-induced accumulation of peroxides, elevation of $\left[\mathrm{Ca}^{2+}\right]_{i}$ and neurotoxicity, and increase antioxidant enzyme activities in hippocampal neurons. J Neurochem 1995;65:1740-51.

[79] Mattson MP. Cellular actions of beta-amyloid precursor protein and its soluble and fibrillogenic derivatives. Physiol Rev 1997;77:1081132.

[80] Mattson MP. Neuroprotective signal transduction: relevance to stroke. Neurosci Biobehav Rev 1997;21:193-206.

[81] Mattson MP, Lindvall O. Neurotrophic factor and cytokine signaling in the aging brain. In: Mattson MP, Geddes JW, editors. The aging brain (Greenwich CT: JAI Press), Adv Cell Aging Gerontol 1997;2:299-345.

[82] Mattson MP, Goodman Y, Luo U, Fu W, Furukawa K. Activation of NF- $\mathrm{B}$ protects hippocampal neurons against oxidative stress-induced apoptosis: evidence for induction of Mn-SOD and suppression of peroxynitrite production and protein tyrosine nitration. J Neurosci Res 1997;49:681-97.

[83] Mattson MP. Modification of ion homeostasis by lipid peroxidation: roles in neuronal degeneration and adaptive plasticity. Trends Neurosci 1998;21:53-7.

[84] Mattson MP, Guo ZH, Geiger JD. Secreted form of amyloid precursor protein enhances basal glucose and glutamate transport and protects against oxidative impairment of glucose and glutamate transport in synaptosomes by a cyclic GMP-mediated mechanism. J Neurochem 1999;73:532-7.

[85] Mattson MP. Apoptosis in neurodegenerative disorders. Nat Rev Mol Cell Biol 2000;1:120-9.

[86] Mattson MP. Creatine: prescription for bad genes and a hostile environment? Trends Neurosci 2000;23:511.

[87] Mattson MP, Camandola S. NF-кB in neurodegenerative disorders. J Clin Invest 2001;107:247-54.

[88] Mattson MP, Pandita TE, editors. Telomerase, aging and disease. Amsterdam: Elsevier, 2001.

[89] Mattson MP, Fu W, Zhang P. Emerging roles for telomerase in regulating cell differentiation and survival: a neuroscientist's perspective. Mech Ageing Dev 2001;122:659-71.

[90] Mattson MP, Duan W, Lee J, Guo Z. Suppression of brain aging and neurodegenerative disorders by dietary restriction and environmental enrichment: molecular mechanisms. Mech Ageing Dev 2001;122:757-78.

[91] Mayeux R, Costa R, Bell K, Merchant C, Tung MX, Jacobs D. Reduced risk of Alzheimer's disease among individuals with low calorie intake. Neurology 1999;59:S296-7.

[92] Mehler MF, Mabie PC, Zhu G, Gokhan S, Kessler JA Developmental changes in progenitor cell responsiveness to bone morphogenetic proteins differentially modulate progressive CNS lineage fate. Dev Neurosci 2000;22:74-85.

[93] McDonald JW, Liu XZ, Qu Y, Liu S, Mickey SK, Turetsky D, et al. Transplanted embryonic stem cells survive, differentiate and promote recovery in injured rat spinal cord. Nat Med 1999;5: $1410-2$. 
[94] Mezey E, Chandross KJ. Bone marrow: a possible alternative source of cells in the adult nervous system. Eur J Pharmacol 2000;405:297302.

[95] Miller FD, Pozniak CD, Walsh GS. Neuronal life and death: an essential role for the p53 family. Cell Death Differ 2000;7:880-8.

[96] Munch G, Thome J, Foley P, Schinzel R, Riederer P. Advanced glycation end products in ageing and Alzheimer's disease. Brain Res Rev 1997;23:134-43.

[97] Nilsson M, Perfilieva E, Johansson U, Orwar O, Eriksson P. Enriched environment increases neurogenesis in the adult rat dentate gyrus and improves spatial memory. J Neurobiol 1999;39: 569-78.

[98] Papaioannou N, Tooten PC, van Ederen AM, Bohl JR, Rofina $\mathrm{J}$, Tsangaris $\mathrm{T}$, et al. Immunohistochemical investigation of the brain of aged dogs. I. Detection of neurofibrillary tangles and of 4-hydroxynonenal protein, an oxidative damage product, in senile plaques. Amyloid 2001;8:11-21.

[99] Pedersen WA, Chan SL, Mattson MP. A mechanism for the neuroprotective effect of apolipoprotein E: isoform-specific modification by the lipid peroxidation product 4-hydroxynonenal. J Neurochem 2000;74:1426-33.

[100] Polymeropoulos MH, Lavedan C, Leroy E, Ide SE, Dehejia A, Dutra A, et al. Mutation in the alpha-synuclein gene identified in families with Parkinson's disease. Science 1997;276:2045-7.

[101] Rao MS, Mattson MP. Stem cells and aging: expanding the possibilities. Mech Ageing Dev 2001;122:713-34.

[102] Richard F, Amouyel P. Genetic susceptibility factors for Alzheimer's disease. Eur J Pharmacol 2001;412:1-12.

[103] Roman GC. Neuroepidemiology of amyotrophic lateral sclerosis: clues to aetiology and pathogenesis. J Neurol Neurosurg Psychiatry 1996;61:131-7.

[104] Roth GS, Joseph JA. Cellular and molecular mechanisms of impaired dopaminergic function during aging. Ann NY Acad Sci 1994;719:129-35.

[105] Saito S, Kobayashi S, Ohashi Y, Igarashi M, Komiya Y, Ando S. Decreased synaptic density in aged brains and its prevention by rearing under enriched environment as revealed by synaptophysin contents. J Neurosci Res 1994;39:57-62.

[106] Samii A, Markopoulou K, Wszolek ZK, Sossi V, Dobko T, Mak E, et al. PET studies of Parkinsonism associated with mutation in the alpha-synuclein gene. Neurology 1999;53:2097-102.

[107] Schwab ME. Regenerative nerve fiber growth in the adult central nervous system. News Physiol Sci 1998;13:294-8.

[108] Shadlen MF, Larson EB. What's new in Alzheimer's disease treatment? Reasons for optimism about future pharmacologic options. Postgrad Med 1999;105:109-18.

[109] Shors TJ, Miesegaes G, Beylin A, Zhao M, Rydel T, Gould E. Neurogenesis in the adult is involved in the formation of trace memories. Nature 2001;410:372-6.

[110] Sloane JA, Hollander W, Moss MB, Rosene DL, Abraham CR. Increased microglial activation and protein nitration in white matter of the aging monkey. Neurobiol Aging 1999;20:395-405.
[111] Sohal RS, Agarwal S, Candas M, Forster MJ, Lal H. Effect of age and caloric restriction on DNA oxidative damage in different tissues of C57BL/6 mice. Mech Ageing Dev 1994;76:215-24.

[112] Sousa N, Lukoyanov NV, Madeira MD, Almeida OF, Paula-Barbosa MM. Reorganization of the morphology of hippocampal neurites and synapses after stress-induced damage correlates with behavioral improvement. Neuroscience 2000;97:253-66.

[113] Sun Y, Nadal-Vicens M, Misono S, Lin MZ, Zubiaga A, Hua $\mathrm{X}$, et al. Neurogenin promotes neurogenesis and inhibits glial differentiation by independent mechanisms. Cell 2001;104:365-76.

[114] Tan EK, Khajavi M, Thomby JI, Nagarnitsu S, Jankovic J, Ashizawa $\mathrm{T}$. Variability and validity of polymorphism association studies in Parkinson's disease. Neurology 2000;55:533-8.

[115] Tanigaki K, Nogaki F, Takahashi J, Tashiro K, Kurooka H, Honjo T. Notch-1 and Notch-3 instructively restrict bFGF-responsive multipotent neural progenitor cells to an astroglial fate. Neuron 2001;29:45-55.

[116] Tobin AJ, Signer ER. Huntington's disease: the challenge for cell biologists. Trends Cell Biol 2000;10:531-6.

[117] van Praag H, Kemperrnann G, Gage FH. Running increases cell proliferation and neurogenesis in the adult mouse dentate gyrus. Nat Neurosci 1999;2:266-70.

[118] Vatassery GT, Bauer T, Dysken M. High doses of Vitamin E in the treatment of disorders of the central nervous system in the aged. Am J Clin Nutr 1999;70:793-801.

[119] Veldman BA, Wijn AM, Knoers N, Praamstra P, Horstink MW. Genetic and environmental risk factors in Parkinson's disease. Clin Neurol Neurosurg 1998;100:15-26.

[120] Walton M, Henderson C, Mason-Parker S, Lawlor P, Abraham WC, Bilkey D, et al. Immediate early gene transcription and synaptic modulation. J Neurosci Res 1999;58:96-106.

[121] Weindruch R, Sohal RS. Seminars in medicine of the Beth Israel Deaconess Medical Center. Caloric intake and aging. N Engl J Med 1997;337:986-94.

[122] Wiese S, Digby MR, Gunnersen JM, Gotz R, Pei G, Holtmann B, et al. The antiapoptotic protein ITA is essential for NGF-mediated survival of embryonic chick neurons. Nat Neurosci 1999;2:978-83.

[123] Yandava BD, Billinghurst LL, Snyder EY. "Global" cell replacement is feasible via neural stem cell transplantation: evidence from the dysmyelinated shiverer mouse brain. Proc Natl Acad Sci USA 1999;96:7029-34.

[124] Yu ZF, Mattson MP. Dietary restriction and 2-deoxyglucose administration reduce focal ischemic brain damage and improve behavioral outcome: evidence for a preconditioning mechanism. J Neurosci Res 1999;57:830-9.

[125] Yu ZF, Luo H, Fu W, Mattson MP. The endoplasmic reticulum stress-responsive protein GRP-78 protects neurons against excitotoxicity and apoptosis: suppression of oxidative stress and stabilization of calcium homeostasis. Exp Neurol 1999;155:302-14.

[126] Zhu H, Guo Q, Mattson NP. Dietary restriction protects hippocampal neurons against the death-promoting action of a presenilin-1 mutation. Brain Res 1999;842:224-9. 